\begin{tabular}{|c|c|c|}
\hline \multirow{2}{*}{ Tone. } & \multicolumn{2}{|c|}{$\begin{array}{l}\text { Observed just Perceptible Difference of } \\
\text { Pitch in Cents. }\end{array}$} \\
\hline & Delezenne. & Külpe. \\
\hline $\begin{array}{r}120 \\
260 \\
500 \\
1000\end{array}$ & $\begin{array}{l}6 \\
\ldots \\
I \cdot 0 \\
0 \cdot 8_{4}\end{array}$ & $\begin{array}{c}\ldots \\
\mathrm{x} \cdot 24 \\
\ldots \\
\ldots\end{array}$ \\
\hline
\end{tabular}

The values for " the time to reach silence" would permit a shake or trill of the following number of tones per second to be clearly heard.

\begin{tabular}{|c|c|}
\hline Tone. & No. of Notes per Second clearly audible. \\
\hline $\mathrm{I} 28$ & $\mathrm{I} 4 \cdot 5$ \\
256 & $23 \cdot 0$ \\
$5 \mathrm{I} 2$ & $40 \cdot 0$ \\
$\mathrm{IO24}$ & $67 \cdot 0$ \\
\hline
\end{tabular}

Unfortunately, I know of no extended experimental results by which these values can be checked. They fit, however, Helmholtz's statement that a shake or trill of ro notes per second, which is clear for tones above about I Io vibrations per sec., ceases to be clear below that pitch.

With regard to the least and greatest differences of pitch between two tones for audible beats, the calculated and observed values appear to fit well. Perhaps I may finish this letter by asking Mr. Wilkinson if these values also fit in with the data at his disposal.

Lastly, being a physiologist, I cannot agree with Prof. Scripture's suggestion (p. I94) that the resonance theory is unthinkable to those who work with delicate human tissues. Neither can I take seriously his proposal that the resonance theory be abandoned and his own substituted. The resonance theory has so far passed every test that I have put to it. Why then think of abandoning it? If I had any doubts lurking in my mind concerning it, or if I thought that it had need to fear rivals, I might, with the editor's permission, tell Prof. Scripture exactly what I think of his theory. But, as neither is the case, I feel there is no need for me to do this. If I have a regret, it is that Prof. Scripture is not as familiar with resonators as he apparently is with delicate human tissues.

King's College, Cambridge.

H. HARTRIDGE.

\section{On Early Sexual Maturity in the Molluscs, Syndosmya alba and Cardium fasciatum.}

IN November I920, good numbers of the mollusc Syndosmya alba round about $15 \mathrm{~mm}$. in length and sexually mature were taken by dredging in the Black Deep near the Edinburgh Lightship. The occurrence of this bivalve, practically on the spot where munitions had recently been dumped, is a matter of much interest, so that observations on the life-history of this form are worth recording. It was suspected at the time that the specimens taken in 1920 were at least six months old, as estimated from material obtained in the sea experimentally, but recently the present writer had the good fortune to obtain a good fall of young ones of this species in a cage which had been in the sea in the River Blackwater in the Thames Estuary area about eight months, i.e. from October 22, I923, to June 7,1924 . In this case the valves of Pecten maximus and Ostrea edulis were strung on tarred rope in pairs, so that pairs of the shells were in the same relative position as in life. In the cavity of these shells a certain amount of mud accumulated, and in this nidus young Syndosmya settled at some time later and grew to a size varying from 6.5 to I $2.0 \mathrm{~mm}$. in length. Individuals about $8.0 \mathrm{~mm}$. in length were found to be approaching sexual maturity.

An artificial fertilisation was made on June 8, 1924 , from a ripe male and female $I I .5$ and $x 2.0 \mathrm{~mm}$. long, respectively, after the eggs had matured in the seawater for one hour. It was found that in less than five minutes the ripe egg threw out a large very transparent membrane ; in about three hours embryos in two to seven celled stages occurred, and in twentyfour hours a ciliated larva ; in less than forty-eight hours a fully formed trochosphere developed with a fine apical tuft resembling the similar stage in the Gastropod, Patella. In a similar experiment male and female Cardium fasciatum 8.3 and $8.5 \mathrm{~mm}$. long were obtained sexually mature, and yielded a thinshelled veliger in the double egg-case in less than fortyeight hours, and a good shelled larva in four days.

Similar material of Syndosmya and Cardium had been obtained in previous years in a period of three to four summer months, but in circumstances where age determination was less certain.

It is a very difficult matter to grow animals of this kind in the sea and be absolutely certain of their age; in the experiment quoted above there is a faint possibility that some of the Syndosmya may have been washed between the shells, although the chance is very remote, as the cage in which the shells were fixed was specially raised 3 feet from the bed of the sea. An experiment has been devised, however, to obtain more information. A point of interest about the early trochosphere of Syndosmya is that it changes its direction of revolution in the egg-capsule in a rhythmical manner which apparently varies with the physical conditions.

At the same time as Syndosmya and Cardium were growing to sexual maturity, European oysters $(O$. edulis) settled in a similar situation and grew to a size of more than one inch long by one inch deep, while Portuguese oysters (O. angulata) grew to as much as $32.6 \mathrm{~mm}$. long by $44^{\circ} \mathrm{O} \mathrm{mm}$. deep, although the young oysters of both kinds were mostly less than half an inch long at the end of last year's growth. Thus, although the sexually mature Syndosmya and Cardium cannot be more than eight months old, there is good reason to infer that they may be much younger, especially as the shells showed mostly no indication of a winter ring. It is probable that both these forms mature in summer in about three or four months.

Marine Biological Laboratory, J. H. ORTON. Plymouth, July 24.

\section{The Reported Transmutation of Mercury into Gold.}

IN your account of the reported discovery, by Prof. Miethe, of the transmutation of mercury into gold (NATuRE, Aug. 9, p. I97) by the prolonged action of a high-tension electric current upon it, you seem to consider only one way, and that not the more obvious way, of effecting such a transmutation, namely, by striking out a hydrogen ion from the nucleus by some powerful method of disruption. There is another method of effecting such a change, namely, by attaching an electron to the mercury nucleus. Indeed, for some time before Prof. Miethe's announcement it has been clear to me that, by passing a sufficiently high tension discharge through mercury vapour, not merely that such a transmutation might occur, but that it was inevitable, unless our present views of atomic structure are radically at fault.

For consider the collision of high-speed electrons with mercury atoms. A small proportion of these

$$
\text { NO. } 2859 \text {, VOL. I I } 4]
$$

